\title{
Larger head circumference in Icelandic children 0-4 years of age compared to the World Health Organization and Swedish growth charts
}

Petur B. Juliusson ${ }^{1,2,3 *}$, Atli Dagbjartsson ${ }^{4,5}$ Mathieu Roelants ${ }^{6}$, Gestur Palsson ${ }^{4}$, Hildigunnur Fridjonsdottir ${ }^{4}$, Rosa Einarsdottir ${ }^{4}$, Arni V. Thorsson ${ }^{4,5}$

${ }^{1}$ Department of Clinical Science, University of Bergen, Bergen, Norway; ${ }^{2}$ Department of Paediatrics, Haukeland University Hospital, Bergen, Norway; ${ }^{3}$ Department of Health Registries, Norwegian Institute of Public Health, Bergen, Norway; ${ }^{4}$ Department of Paediatrics, Landspítalinn University Hospital, Reykjavik, Iceland; ${ }^{5}$ Faculty of Medicine, University of Iceland, Reykjavik, Iceland ; ${ }^{6}$ Environment and Health/Youth health Care, Department of Public Health and Primary Care, KU Leuven, University of Leuven, Belgium

*Address correspondence to:

Petur B. Juliusson, University of Bergen, Department of Clinical Science, N-5021 Bergen, Norway. Email: petur.juliusson@uib.no. Telephone: +47 559750 00. Fax number: +47 55975147

\section{ABSTRACT}

Background. The World Health Organization (WHO) published universal growth standards for children below five year of age in 2006. Traditionally, Swedish growth references have been used to monitor growth of children in Iceland, but it is not yet known how they compare to these reference charts.

Materials. A total of 2128 longitudinal measurements of length or height, 2132 of weight and 2126 of head circumference between birth and four years of age were collected in 19962000 from 199 healthy children (53\% boys) recruited at Landspitali University Hospital. Measurements were converted to z-scores using the WHO growth standards and Swedish growth references for further analysis with mixed effects models.

Results. Length or height, weight and in particular head circumference largely exceeded the WHO standards, with average z-scores that fluctuated between 0.5 and 1.5. Likewise the 
proportion of children with a z-score larger than 2 SD increased about 10-fold. Icelandic children were longer and heavier than their Swedish peers during the first six months of life, but differences were less pronounced thereafter.

Conclusion. The growth of Icelandic children deviated significantly from the WHO growth standards. Although more comparable to the Swedish references, significant differences were found, suggesting that a national growth reference would be more appropriate.

\section{KEY WORDS}

Growth anthropometry, growth reference, growth standards, head circumference, Iceland

\section{KEY NOTES}

- Population variation in growth challenges the use of universal growth charts.

- Data from Icelandic children aged 0 to 4 years were compared with the WHO universal growth standards and the Swedish growth charts that are in routine clinical use in Iceland. - The Icelandic children were taller and heavier compared with the WHO growth standards and with the Swedish references in early infancy. Differences were most pronounced for head circumference.

\section{BACKGROUND}

Monitoring the growth of children is a part of routine paediatric care. Because of population differences in childhood growth, population-specific growth charts are traditionally used as a reference. Such references show the growth of healthy children in a given geographical area at a given time point, and are usually periodically updated due to secular trends that reflect improvements in living conditions and health care (1).

Under the assumption that all children grow alike under optimal environmental conditions, the World Health Organization (WHO) published universal growth standards based on data 
from six countries (2). Children in this study were breastfed and lived in well-off families, with a mother who did not smoke during or after pregnancy.

Growth of children in Western and Northern European countries was shown to deviate from the WHO growth standards, also when using the same inclusion criterion (3). This questions the concept of a universal growth pattern and validity of the standards. Most studies found more pronounced differences for head circumference $(3,4,5)$. Also, studies in clinical populations showed that up-to-date national growth references are superior to the WHO standards when diagnosing conditions that affect growth, like growth hormone deficiency and Turner syndrome $(6,7)$.

Swedish growth charts are traditionally used to monitor growth in Icelandic children. A growth study conducted in 1996-2000 showed that the height of Icelandic schoolchildren was similar to the existing Swedish references $(8,9)$, but the data in children below four years of age were not analysed or published before. In the current study we aim at comparing growth in a cohort of 0-4 year-old Icelandic children with the WHO growth standards, as an international yardstick of growth of children, and with the locally used Swedish growth charts.

\section{METHODS}

\section{Study population and data collection}

Longitudinal measurements of a convenience sample of 199 healthy newborns (53\% boys) were collected in the study during 1996-2000. All children were born between February and December 1996 at Landspitali University Hospital which covered about 70\% of all deliveries in Iceland during the study period. Approximately $8 \%$ of the children born at the hospital during this period were included. Inclusion criteria were full-term (37-42 weeks) single born healthy infants of Icelandic origin. The children were measured at the Pediatric out-patient clinic of the National Hospital of Iceland in Reykjavik with an interval of approximately 3 months during the first two years of life, and every 6 months thereafter. All measurements were taken once using a standardized technique by two paediatricians and two nurses 
working in teams of two. Supine length was measured up to two years of age with a Harpenden infant measurement table (Holtain Ltd, Crosswell, UK) and standing height with Harpenden stadiometer (Holtain Ltd, Crosswell, UK) thereafter. Both were measured and recorded to the nearest millimetre. Weight was measured to the nearest $10 \mathrm{~g}$ with a Seca digital infant weight scale (Seca, Hamburg, Germany) until age of 2, and thereafter to the nearest $100 \mathrm{~g}$ with a Seca digital personal scale (Seca, Hamburg, Germany). Head circumference was the maximal fronto-occipital circumference, measured to the nearest millimetre with a Lufkin W606PM tape (Apex Tool Group, Maryland, USA) placed just above the glabella. All available measurements were included in the analysis, but each child occurs only once in each age group. The feeding type, was recorded as breast, formula or mixed at each contact during infancy. Information on socio-economic or smoking status was not recorded.

\section{Data analysis}

All measurements of length or height, weight, BMI and head circumference were converted to z-scores using the WHO growth standards (2) and the Swedish reference (9). Descriptive statistics are presented in the tables as the mean z-score, standard deviation (SD), and proportion of children with a z-score below -2 SD and above +2 SD. Mean z-scores and proportions are listed in the text with a 95\% confidence interval. If the reference curve matches the population under study, we expect a mean z-score of 0 , a standard deviation of 1 , and a proportion of the observations above +2 SD or below -2 SD of $2.3 \%$ each. The mean z-score can also be interpreted as a mean difference between the sample and reference population, expressed as a number of standard deviations. Global differences between the study population and growth references were analysed with linear mixed-effects models with subject ID as a random factor. Data were analysed in $\mathrm{R}$ version 3.5 ( $\mathrm{R}$ development Core Team, Vienna, Austria, 2018). Linear mixed effects models were estimated with the nlme package in $\mathrm{R}$.

\section{Ethical considerations}

This study complies with declaration of Helsinki and was approved by the Ethics Committee of Landspitali University Hospital. 


\section{RESULTS}

In total 2128 measurements of length or height, 2132 of weight and 2126 of head circumference from 199 children (53\% boys), were included into the analysis. The pattern of z-scores by age was for both growth references remarkably similar in boys and in girls (Figure 1). Data from boys and girls were therefore combined for further analysis, but sex specific data are provided as a supplementary table (Table S1).

The length or height of Icelandic children was overall $0.62(0.52-0.72)$ SD above the WHO standards $(p<0.001)$, but differences were up to 1.25 SD during the first 15 months and down to 0.3SD thereafter (Table 1). Likewise, the percentage of children above 2SD fluctuated between $15.7 \%$ at birth and $2.5 \%$ by the end of the study period. Differences were smaller compared to the Swedish references, with an overall mean $(95 \% \mathrm{Cl}) \mathrm{z}$-score of $0.37(0.27-0.47, p<0.001)$, and similar age patterns (Figure 1, Table1).

The Icelandic children were overall $0.65(0.55-0.75)$ SD heavier when compared with the WHO standard $(p<0.001)$, but age specific means fluctuated between 0.32 and 0.92 SD (Table 1). Weight was more comparable with the Swedish reference (mean 0.09 SD, -0.02 $0.20 S D, p=0.1$ ), but larger during the first months (up to $0.74 S D$ ) than thereafter (down to $-0.2 \mathrm{SD}$ ) (Table 1). The overall mean BMI z-score was $0.43(0.33-0.53, p<0.001)$ relative to the WHO standard, and $-012(-0.23--0.01, p=0.03)$ relative to the Swedish reference. There was however considerable age variation (Figure 1, Table 1).

The head circumference of Icelandic children was considerably larger compared to the WHO growth standard, with an overall mean z-score of $1.30(1.17-1.43, p<0.001)$. This phenomenon was fairly consistent across all age groups (Figure 1, Table 1). The proportion of children with a z-score above +2 SD was up to 10 times larger than expected (Table 1 ). The overall mean head circumference $z$-score was $0.39(0.26-0.52)$ compared to the Swedish reference $(p<0.001)$, with some differences according to age (Figure1, Table 1$)$. Up to $13.7 \%$ of heads were above 2SD but this number was much smaller (down to $1.6 \%$ ) by the end of the study period (Table 1). 
All except 3 children were breastfed at birth (98.5\%). By the age of 3 months 168 children (85.3\%) were breastfed, of whom 116 (58.2\%) exclusively, and by the age of 6 months 126 children (64.2\%) were breastfed, of whom 25 (12.6\%) exclusively. The mean (SD) duration of any breastfeeding was $0.47(0.30)$ years, but only $0.18(0.17)$ years for exclusive breastfeeding.

\section{DISCUSSION}

In the present study we found that length, weight and particularly head circumference of Icelandic children exceeded the WHO growth standards. Differences were much smaller when compared with the Swedish growth charts, especially after the first year of life. The observed differences in head circumference, height and weight/BMI in children aged 0-1.5 years, should be acknowledged, and suggests a need for growth references for Icelandic children.

The Icelandic children had, in particular, a large head circumference when compared with the WHO. The methodology in the current study was comparable with that from the WHO Multicentre Growth Reference Study (10), using the same anatomical landmarks with a nonstretch measurement tape placed just above the eyebrows (glabella) and the largest protuberance at the back of the head. All measurements in the Icelandic growth study were taken by experienced health care professionals, so the data were presumed to be of high quality. Although head sizes were closer to the Swedish references, the head circumference was still significantly larger during the first year of life in both sexes, but differences disappeared thereafter. However, the fairly large decrease relative to the Swedish growth charts implies that a worryingly increase in head circumference could be partly ablated when using this as a reference to monitor head growth in Icelandic children. Crossing one percentile channel $(0.67 \mathrm{SD})$ on the chart between 0.5 and 1 year of age would actually mean that the child crosses approximately two percentile channels compared to its peers. It has been documented before that significant population differences in head circumferences exist $(3,4,11,12)$. Routine monitoring of head circumference is particularly important during the first year of life, in order to detect children with a pathologically increased head growth 
(as seen in children with an increased intra-cranial pressure, for instance), or children with microcephaly. Although crossing of centiles can be detected regardless the chart being used, it becomes harder when children are on average tracking downward, as is the case for the Swedish reference charts. Also, erroneously misclassifying heads as being too large (as is the case for the WHO standards) can be problematic, and may lead to unnecessarily worries and clinical investigations. This has recently been acknowledged in Norway, where the guidelines have been revised, and now recommend the national reference for head circumference instead of the WHO growth standards (13).

The differences in height, weight and BMI were smaller than for head circumference, but still on average above 0.5 SD in early infancy. In the WHO Multicentre Growth Reference Study no site differences were larger than $0.5 \mathrm{SD}$, and most were less than $0.2 \mathrm{SD}$, which was considered as minor (14). Differences relative to the WHO growth charts in Western populations are usually attributed to feeding practices, but studies in breastfed children have repeatedly demonstrated that this does not explain all observed difference. This suggests a persistent influence of the genetic background or involvement of environmental factors not covered in the WHO growth study $(3,15)$. The rate of breastfeeding in the Icelandic children, although below that in the WHO Multicentre Growth Reference Study, was above the breastfeeding rate found in Sweden in the 1970s (16).

Although our data were originally collected in the years 1996-2000, this is closer to the WHO Multicentre Growth Reference Study window, i.e. 2001-2004, than a recent study would be. Regarding the applicability of our results to contemporary Icelandic children, there is no reason to believe that size differences would have become smaller over time, at least not in children born of parents of Icelandic origin. The Swedish references are based on longitudinal data of children from Gothenburg who were born between 1970-75 (9).

The strengths of this study was the robust methodology used and the relatively high degree of homogeneity of the study population when the data were collected. A limitation is to some extent the age of the data. However, it is worth noting that our findings regarding the head circumference, length and weight relative to the WHO growth standards, have been observed in other populations before. Another limitation is the number of children in the 
study, however, this is compensated by the number of measurements performed on each child. Although the dataset is robust enough to make comparisons, higher number of children should be included for estimating reference charts.

\section{CONCLUSION}

Icelandic children from birth to four year of age, were found to be taller, heavier and, in particular, with a larger head circumference when compared with the WHO growth standards. Age dependent differences are also present when compared with the locally used Swedish growth references, especially during the first year of life. Neither reference curve seems optimal to monitor growth in Icelandic children which suggests the need for a national growth reference based on the local population.

\section{ACKNOWLEDGEMENTS}

We would like to thank all the families participating in the study.

\section{ABBREVIATIONS}

BMI - body mass index; MGRS - Multicentre Growth Reference Study.

\section{FUNDING}

No external funding was secured for this study.

\section{CONFLICT OF INTEREST}

The authors declare no conflict of interests. 


\section{REFERENCES}

1. Hauspie RC, Vercauteren M, Susanne C. Secular changes in growth and maturation: an update. Acta Paediatr Suppl 1997; 423: 20-7.

2. WHO Child Growth Standards based on length/height, weight and age. Acta Paediatr Suppl 2006;450:76-85.

3. Juliusson PB, Roelants M, Hoppenbrouwers K, Hauspie R, Bjerknes R. Growth of Belgian and Norwegian children compared to the WHO growth standards: prevalence below -2 and above +2 SD and the effect of breastfeeding. Arch Dis Child, 96 (2011), pp. 916-921.

4. Natale V, Rajagopalan A. Worldwide variation in human growth and the World Health Organization growth standards: a systematic review. BMJ Open, 4 (2014), p. e003735.

5. Tinggaard J, Aksglaede L, Sørensen K, Mouritsen A, Wohlfahrt-Veje C, Hagen CP, et al. The 2014 Danish references from birth to 20 years for height, weight and body mass index. Acta Paediatr 2014;103:214-24.

6. Christesen H, Pedersen BT, Pournara E, Petit IO, Juliusson PB. Short Stature: Comparison of WHO and National Growth Standards/References for Height. PLoS One 2016; June 9: DOI:10.1371/journal.pone.0157277.

7. Saari A, Sankilampi U, Dunkel L. Multiethnic WHO growth charts may not be optimal in the screening of disorders affecting height: Turner syndrome as a model. JAMA Pediatr 2013;167:194-5.

8. Dagbjartsson A, Thorsson AV, Palsson GI, Arnórsson VH. Height and weight of Icelandic children 6-20 years of age. Læknablaðið 2000; 86: 509-14. 
9. Albertsson Wikland A, Luo ZC, Niklasson A, Karlberg J. Swedish population-based longitudinal reference values from birth to 18 years of age for height, weight and head circumference. Acta Paediatr 2002;91:739-54.

10. De Onis M, Garza C, Victora CG, et al, for the Multicentre Growth Reference Study Group. The WHO Multicentre Growth Reference Study: planning, study design, and methodology. Food Nutr Bull 2004;25(1 Suppl):S15-26.

11. Amare EB, Idsøe $M$, Wiksnes $M$, Moss $T$, Roelants $M$, Shimelis $D$, Júlíusson PB, Kiserud T, Wester K. Reference Ranges for Head Circumference in Ethiopian Children 0-2 Years of Age. World Neurosurg 2015;84:1566-71.

12. Wright CM, Inskip HM, Godfrey K, Williams AF, Ong KK. Monitoring head size and growth using the new UK-WHO growth standard. Arch Dis Child, 96 (2011), pp. 386-388.

13. https://helsedirektoratet.no/retningslinjer/helsestasjons-ogskolehelsetjenesten/seksjon?Tittel=veiing-og-maling-20014759\#hodeomkrets:helsestasjonen-b\%C3\%B8r-m\%C3\%A5le-hodeomkrets-p\%C3\%A5-barn-0-2-\%C3\%A5rsterkanbefaling

14. WHO Multicentre Growth Reference Study Group. Assessment of differences in linear growth among populations in the WHO Multicentre Growth Reference Study. Acta Paediatr 2006;(Suppl 450):56-65.

15. Roelants M, Hauspie R, Hoppenbrouwers K. Breastfeeding, growth and growth standards: Performance of the WHO growth standards for monitoring growth of Belgian children. Ann Hum Biol. 2010;37:2-9.

16. Yngve A, Sjöström. Breastfeeding in countries of the European Union and EFTA: current and proposed recommendations, rationale, prevalence, duration and trends. Public Health Nutrition 2001;4:631-45. 
Table 1. Length or height (HAZ), weight (WAZ), BMI (BMIAZ) and head circumference (HCAZ) z-scores of Icelandic children compared to the WHO growth standard (2) and the Swedish growth references (8) (mean z-scores, SD and percentage below -2 SD ( $P<-2)$ and above 2 SD $(P>2)$.

\begin{tabular}{|c|c|c|c|c|c|c|c|c|c|}
\hline \multirow[b]{2}{*}{ Age } & \multirow[b]{2}{*}{$\mathbf{N}$} & \multicolumn{4}{|c|}{ WHO2006 } & \multicolumn{4}{|c|}{ Swedish growth reference } \\
\hline & & Mean & SD & $<-2(\%)$ & $>2(\%)$ & Mean & SD & $<-2(\%)$ & $>2(\%)$ \\
\hline \multicolumn{10}{|c|}{ HAZ, Length or height for age z-scores } \\
\hline 0 & 198 & 1.25 & 0.75 & 0 & 15.66 & 0.68 & 0.67 & 0 & 2.53 \\
\hline 0.25 & 197 & 0.75 & 0.77 & 0 & 6.09 & 0.69 & 0.75 & 0 & 4.06 \\
\hline 0.5 & 196 & 0.79 & 0.76 & 0 & 6.12 & 0.55 & 0.77 & 0 & 2.55 \\
\hline 0.75 & 192 & 0.73 & 0.85 & 0 & 7.29 & 0.44 & 0.85 & 0 & 4.17 \\
\hline 1 & 184 & 0.74 & 0.85 & 0 & 6.52 & 0.53 & 0.84 & 0 & 4.89 \\
\hline 1.25 & 180 & 0.75 & 0.9 & 0 & 6.67 & 0.56 & 0.89 & 0 & 5.56 \\
\hline 1.5 & 185 & 0.33 & 0.86 & 0 & 4.32 & 0.07 & 0.85 & 0.54 & 1.62 \\
\hline 1.75 & 177 & 0.3 & 0.86 & 0.56 & 3.39 & 0.12 & 0.85 & 0.56 & 2.26 \\
\hline 2 & 167 & 0.35 & 0.87 & 0 & 2.99 & 0.09 & 0.86 & 0 & 1.8 \\
\hline 2.5 & 156 & 0.34 & 0.83 & 0 & 2.56 & 0.12 & 0.84 & 0.64 & 1.92 \\
\hline 3 & 158 & 0.34 & 0.81 & 0 & 2.53 & 0.11 & 0.83 & 0.63 & 2.53 \\
\hline 3.5 & 121 & 0.32 & 0.8 & 0 & 2.48 & 0.12 & 0.83 & 0 & 2.48 \\
\hline \multicolumn{10}{|c|}{ WAZ, weight for age z-scores } \\
\hline 0 & 198 & 0.92 & 0.68 & 0 & 8.59 & 0.5 & 0.66 & 0 & 0 \\
\hline 0.25 & 197 & 0.32 & 0.8 & 0 & 1.02 & 0.74 & 0.84 & 0 & 9.14 \\
\hline 0.5 & 196 & 0.47 & 0.89 & 0 & 4.59 & 0.36 & 1.00 & 0 & 6.12 \\
\hline 0.75 & 192 & 0.63 & 0.88 & 0 & 4.69 & 0.04 & 1.03 & 1.56 & 3.12 \\
\hline 1 & 184 & 0.71 & 0.84 & 0 & 6.52 & -0.11 & 1.01 & 2.17 & 1.09 \\
\hline 1.25 & 180 & 0.73 & 0.8 & 0 & 6.11 & -0.13 & 0.96 & 3.33 & 1.67 \\
\hline 1.5 & 185 & 0.78 & 0.8 & 0 & 7.57 & -0.12 & 0.95 & 2.16 & 1.62 \\
\hline 1.75 & 177 & 0.75 & 0.81 & 0 & 5.08 & -0.15 & 0.97 & 2.26 & 2.26 \\
\hline 2 & 167 & 0.69 & 0.81 & 0 & 4.79 & -0.2 & 0.94 & 1.8 & 0.6 \\
\hline 2.5 & 156 & 0.59 & 0.82 & 0 & 3.85 & -0.15 & 0.95 & 2.56 & 1.28 \\
\hline 3 & 158 & 0.55 & 0.8 & 0.63 & 4.43 & -0.08 & 0.91 & 1.9 & 1.9 \\
\hline 3.5 & 121 & 0.47 & 0.74 & 0 & 2.48 & -0.07 & 0.83 & 0.83 & 0.83 \\
\hline \multicolumn{10}{|c|}{ BMIZ, BMI z-score for age z-scores } \\
\hline 0 & 198 & 0.41 & 0.73 & 0 & 2.02 & 0.15 & 0.79 & 0.51 & 2.02 \\
\hline 0.25 & 197 & -0.13 & 0.9 & 2.54 & 1.02 & 1.04 & 0.90 & 0 & 15.23 \\
\hline 0.5 & 196 & 0.03 & 0.98 & 0.51 & 3.06 & 0.3 & 1.06 & 0.51 & 6.63 \\
\hline 0.75 & 192 & 0.29 & 0.89 & 0 & 2.08 & -0.25 & 1.00 & 5.21 & 1.04 \\
\hline 1 & 184 & 0.4 & 0.85 & 0 & 1.63 & -0.62 & 0.96 & 7.07 & 0 \\
\hline 1.25 & 180 & 0.43 & 0.85 & 1.11 & 2.78 & -0.71 & 0.94 & 8.89 & 0 \\
\hline 1.5 & 185 & 0.84 & 0.82 & 0 & 8.11 & -0.3 & 0.89 & 2.7 & 1.08 \\
\hline 1.75 & 177 & 0.82 & 0.83 & 0 & 7.34 & -0.35 & 0.93 & 3.95 & 1.13 \\
\hline 2 & 167 & 0.68 & 0.85 & 0.6 & 3.59 & -0.37 & 0.94 & 6.59 & 0.6 \\
\hline 2.5 & 156 & 0.52 & 0.88 & 0 & 3.85 & -0.33 & 0.99 & 3.85 & 1.28 \\
\hline 3 & 158 & 0.48 & 0.86 & 0 & 4.43 & -0.24 & 0.98 & 5.06 & 0.63 \\
\hline 3.5 & 121 & 0.38 & 0.8 & 0 & 2.48 & -0.26 & 0.93 & 3.31 & 0.83 \\
\hline \multicolumn{10}{|c|}{ HCZ, Head circumference for age z-score } \\
\hline 0 & 198 & 1.4 & 0.99 & 0.51 & 22.73 & 0.35 & 0.69 & 0.51 & 0 \\
\hline 0.25 & 197 & 1.08 & 0.97 & 0 & 17.77 & 0.83 & 0.95 & 0 & 13.71 \\
\hline 0.5 & 196 & 1.16 & 0.97 & 0 & 20.92 & 0.7 & 1.07 & 0.51 & 12.76 \\
\hline 0.75 & 192 & 1.22 & 1.01 & 0 & 20.83 & 0.45 & 1.07 & 1.56 & 7.29 \\
\hline 1 & 184 & 1.28 & 1.03 & 0 & 26.63 & 0.31 & 1.05 & 1.63 & 7.07 \\
\hline 1.25 & 180 & 1.31 & 1 & 0 & 26.67 & 0.29 & 1.03 & 2.22 & 4.44 \\
\hline 1.5 & 185 & 1.44 & 1 & 0 & 31.35 & 0.27 & 1.03 & 1.62 & 4.86 \\
\hline 1.75 & 177 & 1.48 & 0.95 & 0 & 32.2 & 0.33 & 0.99 & 0 & 4.52 \\
\hline 2 & 167 & 1.44 & 1 & 0 & 31.14 & 0.28 & 1.03 & 1.2 & 3.59 \\
\hline 2.5 & 156 & 1.31 & 0.95 & 0 & 26.28 & 0.23 & 1.00 & 1.92 & 2.56 \\
\hline 3 & 158 & 1.32 & 0.98 & 0 & 24.05 & 0.24 & 1.06 & 1.27 & 2.53 \\
\hline 3.5 & 121 & 1.23 & 0.94 & 0 & 20.66 & 0.19 & 1.05 & 1.65 & 1.65 \\
\hline
\end{tabular}





Figure 1. Mean SDS based on WHO growth standard (filled symbols) and the Swedish growth reference (open symbols) in boys (left) and girls (right) for length or height (HAZ), weight (WAZ), BMI (BMIAZ) and head circumference (HCAZ). 